\title{
ANÁLISE DO PROCESSO PRODUTIVO E CAPACIDADE OPERACIONAL DE UMA ORGANIZAÇÃO DE COLETA SELETIVA DE RESÍDUOS SÓLIDOS - ESTUDO DE CASO ASNOV GARANHUNS
}

\section{ANALYSIS OF THE PRODUCTIVE PROCESS AND OPERATIONAL CAPACITY OF A SELECTIVE COLLECTION ORGANIZATION OF SOLID WASTE - ASNOV, GARANHUNS CASE STUDY}

\author{
Ingrid Saiala Cavalcante de Souza Feitosa* E-mail: i.saiala@hotmail.com
}

Gilson Lima da Silva** E-mail: glimasilva21@yahoo.com

*Programa de Pos-Graduação em Engenharia de Produção, Universidade Federal de Pernambuco Centro Acadêmico do Agreste (UFPE-CAA), Caruaru-PE

** Universidade Federal de Pernambuco - Centro Acadêmico do Agreste (UFPE-CAA), Caruaru-PE

Resumo: Gerenciar adequadamente um processo produtivo é determinante para alcançar os objetivos organizacionais, porém a ausência de conhecimento técnico torna essa gestão desafiadora e leva a resultados aquém do que a organização poderia obter. Associações e cooperativas de catadores de materiais recicláveis, bastante relevantes na implantação da gestão integrada de resíduos, através da Política Nacional de Resíduos Sólidos (PNRS), contam, na maior parte das vezes, com um gerenciamento incipiente de seus processos e atividades. Nesse sentido, propôs-se a análise do processo produtivo de uma organização de coleta seletiva de resíduos sólidos recicláveis e reutilizáveis, enfocando sua capacidade de absorver o volume gerado desses resíduos em sua área de atuação. Utilizou-se de questionário semiestruturado e entrevistas, construindo-se o fluxograma do processo, e de mensurações da capacidade operacional da produção. Os resultados obtidos, da organização atuante no município de Garanhuns, Pernambuco, a única a realizar coleta seletiva na cidade, demonstraram sua capacidade operacional de absorver os resíduos recicláveis e reutilizáveis gerados no município. O processo produtivo é apresentado em detalhes e sua capacidade de absorção dos resíduos ainda que pequena, contribui inegavelmente para a redução do volume considerável de resíduos destinados a aterros.

Palavras-chave: Coleta Seletiva. Resíduos sólidos urbanos. Catadores. Processo produtivo. Capacidade.

\begin{abstract}
Managing a productive process properly is the key factor to reach the organization objectives; however, the lack of technical knowledge not only makes the managing process really challenging, but also it produces a result that is below the level that the company could achieve. Even though being one of the most important characters to the implementation of a integrated waste management system, associations and cooperatives of recycling material collectors, through the Brazilian National Solid Waste Policy (NSWP), proclaim to work under a undeveloped managing system. Therefore, it was proposed an analysis of the productive process of a selective solid waste collection organization, focusing on its capacity to absorb the amount of waste produced on its work area. In this analysis, it was made a structured questionnaire, a semi-structured interview and a process flowchart with recognition and measurement of its operational capacity. Moreover, the company analyzed is the only waste collection company located in Garanhuns, Pernambuco. The productive process is presented in detail, and although its operational capacity to absorb solid waste is low, it unequivocally contributes to the reduction of an important amount of waste that previously were destined to landfills.
\end{abstract}

Keywords: Selective collect. Solid waste. Collector. Productive process. Capacity 


\section{INTRODUÇÃO}

Uma organização que se propõe a entregar bens ou serviços através da operacionalização de um processo produtivo e que objetiva manter-se sustentável no mercado em que está inserida necessita de compreensão apurada de seus processos e capacidade. O estudo do sistema ou processo de produção envolve, inicialmente, seu modelo básico, composto de inputs, processo de transformação, e outputs.

A capacidade de um processo produtivo será determinada pelos recursos de que este dispõe para produção de seus outputs e diz respeito ao potencial produtivo do processo. É o máximo nível de atividade de valor adicionado em determinado período de tempo que o processo pode realizar sob condições normais de operação (SLACK; CHAMBERS; JOHNSTON, 2009). O correto planejamento e gerenciamento da capacidade é determinante para uma organização, pois decisões tomadas nesse campo afetam, entre outros, os custos de produção, o desempenho das operações, o atendimento e a manutenção de posicionamento estratégico no mercado.

Em organizações de menor porte, comumente, encontra-se uma gestão em que há ausência de conhecimento técnico necessário ao planejamento e gerenciamento eficiente e eficaz das atividades e, consequentemente, da capacidade organizacional. Não escapam dessa realidade, cooperativas, associações ou ainda organizações sem fins lucrativos. Dentre essas, associações de catadores de material reciclável e reutilizável constituem um ambiente que necessita de suporte técnico de forma a aprimorar a operacionalização de suas atividades, em especial frente à grande área potencial para atuação no cenário nacional atual.

O Brasil encontra-se em fase de implementação da Política Nacional de Resíduos Sólidos (PNRS), instituída pela Lei № 12.305 de 2 de agosto de 2010. A PNRS objetiva implementar uma gestão integrada dos resíduos, com responsabilidades compartilhadas entre empresas privadas, instituições públicas e o terceiro setor, e com a participação de cooperativas e/ou associações de catadores de materiais reutilizáveis e recicláveis formadas por pessoas físicas de baixa renda (LIMA, SILVA, 2013; ALENCAR, SANTOS, 2013; OLIVEIRA; GALVÃO JUNIOR, 2016). 
A gestão dos Resíduos Sólidos Urbanos (RSU), gerados em enormes quantidades, ainda é um desafio para as administrações municipais. As associações e cooperativas de catadores de resíduos sólidos são, em alguns casos, os únicos meios pelos quais municípios contam com a segregação de resíduos sólidos recicláveis e não recicláveis. Entretanto, ainda que possuam grande relevância para um gerenciamento mais adequado de resíduos, a ausência nessas organizações de noções apuradas da capacidade de seu processo ou desempenho de seu sistema torna sua gestão, muitas vezes, desafiadora. Estudos presentes na literatura abordam frequentemente as organizações de catadores de resíduos sólidos em análises e propostas envolvendo as dimensões social, político-institucional e ambiental (AQUINO, CASTILHO JUNIOR, PIRES, 2009; GOMES et al., 2012; MARCONDES, 2012; ALENCAR, SANTOS, 2013; BUQUE, RIBEIRO, 2015; MARQUES, SANTOS, 2016), ocupando-se pouco da análise de sua dimensão produtiva.

Diante do contexto e cenário descritos, o estudo aqui apresentado objetivou analisar o processo produtivo de uma organização de coleta seletiva de resíduos sólidos recicláveis e reutilizáveis, enfocando sua capacidade operacional de absorver a oferta de RSU no setor produtivo em que atua. O estudo é inovador à medida que traz a inserção de conhecimento técnico de gestão da produção nessa categoria de organização. Desenvolver seu potencial como negócio produtivo possibilitaria, por exemplo, parcerias com prefeituras para que essas organizações sejam responsáveis formais pela coleta seletiva em seus municípios.

Através da aplicação de questionário e entrevista semiestruturada, pode-se estudar o sistema de produção da organização com a construção de fluxograma de seu processo. Obtiveram-se, ainda, informações para sua caracterização e de parcela do seu setor produtivo. A avaliação quantitativa da capacidade de operação realizou-se com mensuração da produção, pelo período de um mês (21 dias úteis), e comparação frente ao volume de resíduos sólidos urbanos gerados na área de atuação da organização em igual período.

A associação estudada é a única que desempenha atividades de coleta seletiva no município em que atua, tendo papel relevante para a melhor destinação dos RSU recicláveis e reutilizáveis. Ainda que absorva apenas uma pequena parcela do que é gerado no município, a organização contribui inegavelmente para a 
redução do volume que seria destinado a aterros. Além disso, é fonte de emprego e renda para famílias da região.

\section{REFERENCIAL TEÓRICO}

\section{1 processo produtivo}

Toda atividade de produção, seja seu produto um bem ou um serviço, envolve um processo de transformação. Um processo ou sistema de produção é definido pelo conjunto de input, ou insumos, processo de conversão ou transformação, que são as operações e/ou atividades a serem realizadas a partir dos recursos, outputs, os resultados ou saídas do processo, e ainda um sistema de controle que diz respeito às atividades de monitoração dos demais elementos do sistema de produção (MOREIRA, 2008). Na Figura 1, é possível perceber o modelo básico input-transformação-output de um processo produtivo.

Figura 1 - Modelo básico de um processo produtivo com seus principais elementos

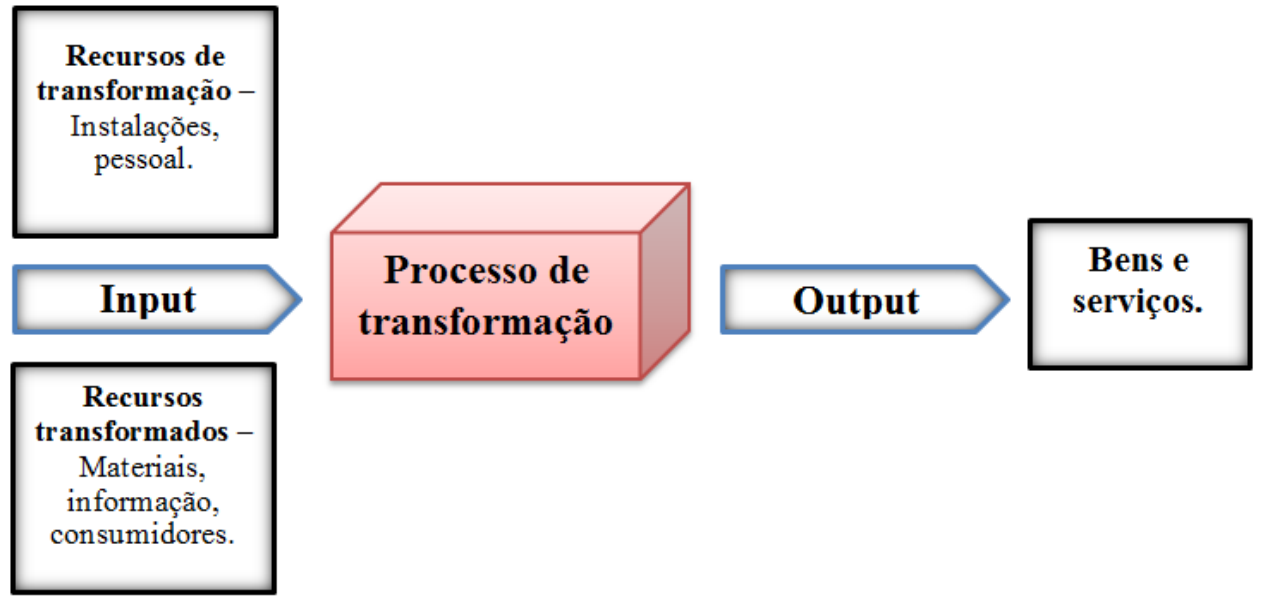

Fonte: Adaptado de Slack, Chambers e Johnston (2009)

Uma representação compacta do curso de um processo produtivo pode ser obtida utilizando um fluxograma, ou gráfico do fluxo do processo (BARNES, 1977). Essa é uma ferramenta largamente empregada em registros de processos industriais e como recurso visual para a análise de sistemas produtivos, auxiliando, por exemplo, na busca e identificação de oportunidades de melhoria na eficiência dos processos (PEINADO; GRAEML, 2007). 
Estudos do processo produtivo com variadas finalidades apresentam o uso do fluxograma entre suas etapas, a exemplo do planejamento de ampliação de capacidade (SOARES, 2010), da melhoria de layout e processos (ROSA et al., 2014) e do direcionamento para escolha de gráficos de controle e índices de capacidade para processos (SOUZA; PEDRINI; CATEN, 2014).

\subsection{Capacidade do processo produtivo}

A capacidade de um sistema ou processo produtivo, função dos recursos disponíveis para a operacionalização de suas atividades, representa a quantidade máxima que pode ser produzida por unidade de produção em determinado intervalo de tempo. Entende-se por unidade de produção, por exemplo, uma fábrica, um armazém, uma máquina ou um posto de trabalho (MOREIRA, 2008).

Uma organização possui uma capacidade teórica de operação e uma capacidade efetiva. A primeira é a capacidade planejada quando as operações foram projetadas e considera a máxima capacidade de utilização, sendo dificilmente atendida na prática. Já a segunda representa a capacidade real do processo, após serem deduzidas todas as perdas advindas de questões técnicas, operacionais ou de mercado sobre a produção (SLACK; CHAMBERS; JOHNSTON, 2009).

As decisões sobre capacidade envolvem a determinação da capacidade total de produção, o planejamento do nível de utilização da capacidade instalada e estratégias de adequação às possíveis sazonalidades do mercado (PAIVA, CARVALHO JUNIOR E FENSTERSEIFER, 2004). Antunes et al. (2008) apresentam a determinação da capacidade com a máxima precisão possível, ainda que não sejam consideradas as eficiências reais dos equipamentos, como uma das questões essenciais da Engenharia de Produção.

Estudos da capacidade de um processo produtivo, independente da abordagem que empreguem, consideram em suas primeiras etapas a determinação do fluxo produtivo e a mensuração da capacidade que a organização pode efetivar (STAUDT, COELHO, GONÇALVES, 2011; PERGHER; VACCARO; PRADELLA, 2013; SOUZA et al., 2014; ALMEIDA; ROMANZINI; WERNER, 2016).

A literatura apresenta estudos com foco na influência da capacidade efetiva sobre os custos de fabricação (SILVA; LEITE, 2013), na utilização da Teoria das Restrições (PACHECO et al., 2012), no planejamento de capacidade numa cadeia 
de suprimentos (XIE et al., 2014), no dimensionamento de capacidade para prestadoras de serviço (JIANG; SEIDMANN, 2014) e na otimização do uso da capacidade (AKşIN et al., 2015; ALMEIDA; ROMANZINI; WERNER, 2016).

\subsubsection{Planejamento e controle de capacidade}

O processo de planejamento e controle da capacidade é apresentado em três etapas por Slack, Chambers e Johnston (2009). A primeira etapa diz respeito à mensuração de níveis agregados de demanda e capacidade, obtendo-se informações quantitativas. Já a segunda refere-se à identificação de políticas alternativas de capacidade que possam ser adotadas para responder às flutuações da demanda. Por último, tem-se a escolha de quais dentre essas políticas é a mais adequada para as circunstâncias da organização. As etapas apresentadas pelos autores supracitados dialogam perfeitamente com as decisões sobre capacidade trazidas por Paiva, Carvalho Junior e Fensterseifer (2004).

O planejamento de capacidade objetiva suprir a demanda ao nível mais exato possível, mas isso se torna uma tarefa complexa devido a restrições, como manter custos em níveis aceitáveis e a flutuações da demanda (LEE, 2016). Uma importante questão do planejamento de capacidade é a decisão de baseá-lo na definição de um nível/escala econômica de capacidade ou no chasing demand (acompanhar a demanda) (OLHAGER; JOHANSSON, 2012; LEE, 2016).

É imprescindível que se conheça a capacidade atual do processo antes de se tomar decisões que visem ampliar o atendimento da demanda ou a atuação no mercado, como, por exemplo, investir em capacidade produtiva na organização (STAUDT; COELHO; GONÇALVES, 2011).

\subsubsection{Mensuração da capacidade produtiva}

A mensuração da capacidade não é um processo simples, sobretudo quando o processo estudado não possui atividades claramente padronizadas e repetitivas. Por essa razão, para medições de capacidade, muitas vezes, serão necessárias suposições ou estimativas (SLACK et al. 2008). Nas operações cujas saídas constituem-se de um mix de produtos ou serviços, é possível utilizar valores de 
capacidade agregada em que se agrupam esses diferentes produtos ou serviços de modo a obter uma visão geral da demanda e capacidade.

Essa prática é aceitável e amplamente utilizada para gerenciamento de capacidade no médio prazo, que corresponde a períodos de 2 a 18 meses (SLACK et al., 2008). No planejamento agregado da produção, agrupa-se a capacidade de processamento de produção como um todo, e não por unidade produtiva. Além disso, agrupam-se os diversos produtos demandados à organização em famílias (MUNHOZ; MORABITO, 2013).

Moreira (2008) afirma que a mensuração da capacidade de uma organização pode ser feita por meio da produção, a exemplo da produção de toneladas/mês ou o número de carros/ano, e por meio dos insumos, como número de vagas ou de assentos disponíveis/voo. A medida de capacidade através do volume de produção é mais apropriada quando a natureza do produto da operação não varia. Em operações que possuem uma gama mais ampla de produtos e cujas demandas apresentam-se variáveis para o processo, medidas de capacidade através dos insumos são utilizadas com mais frequência (SLACK, CHAMBERS E JOHNSTON, 2009). As organizações podem utilizar ainda uma combinação dessas duas formas de medida, ou seja, uma abordagem mista para mensuração da capacidade.

\subsection{Gestão dos Resíduos Sólidos no Brasil}

\subsubsection{Diagnóstico da situação}

De acordo com diagnóstico da Associação Brasileira de Empresas de Limpeza Pública e Resíduos Especiais (ABRELPE) para 2016, a geração per capita de Resíduos Sólidos Urbanos (RSU) no Brasil é de 379.6 kg/hab./ano, equivalente a um total anual de 78.228.511,6 toneladas. Os RSU correspondem aos resíduos domiciliares e de limpeza urbana (varrição, limpeza de logradouros e vias públicas e outros serviços de limpeza urbana) (BRASIL, 2010).

Uma comparação realizada pela ABRELPE (2016) entre a quantidade de RSU gerados e a coletada em 2016 no Brasil mostra que, por ano, cerca de 7 milhões de toneladas deixam de ser coletadas e, por consequência, têm destino impróprio. No gráfico apresentado na Figura 2, observa-se um quantitativo da atividade de coleta de RSU nas regiões brasileiras. Na região Sudeste, essa 
atividade apresenta maior abrangência, tendo 52,7\% dos RSU gerados coletados, seguida pela região Nordeste, com 22,0\%.

Figura 2 - Quantidade (\%) dos RSU gerados que é coletada no Brasil por região

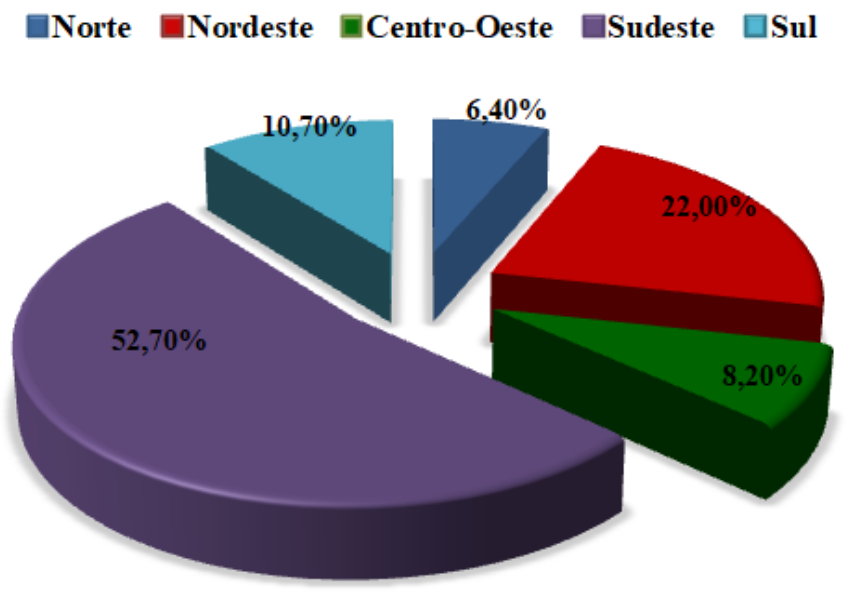

Fonte: Adaptado de ABRELPE (2016)

Quanto à destinação dos RSU coletados, os dados da ABRELPE referentes ao ano de 2016 demonstram que 41,6\% dos resíduos sólidos tiveram destinação final inadequada. Isso representa 32.543.060 toneladas por ano enviadas para lixões ou aterros controlados, os quais diferenciam-se muito pouco de lixões, uma vez que não possuem o conjunto de sistemas necessários à proteção do meio ambiente e da saúde pública (ABRELPE, 2014).

A CEMPRE (2015) afirma que apenas $17 \%$ dos municípios brasileiros contam com um sistema de coleta que segregue os resíduos. Na base do sistema de coleta seletiva desenvolvido no Brasil, estão os catadores de materiais recicláveis. Esse sistema envolve ainda sucateiros de pequeno e grande porte e indústrias recicladoras. Os catadores de materiais recicláveis pertencem à classe que menos se beneficia, visto que as indústrias preferem comprar em grandes quantidades e materiais de qualidade, o que nem sempre pode ser obtido devido à pouca infraestrutura com que a maior parte dos catadores realiza seu trabalho (MEDINA, 2000; AQUINO, CASTILHO JUNIOR, PIRES, 2009). A versão preliminar do Plano Nacional de Resíduos Sólidos cita que há pelo menos 1100 (mil e cem) organizações coletivas de catadores em funcionamento em todo o país (BRASIL, 2011). 
Dados da cadeia produtiva de reciclagem de Resíduos Sólidos Urbanos no Brasil apresentados pela Abrelpe (2016) destacam como setores industriais de participação mais consistente nas atividades de reciclagem os de alumínio, papel e plásticos. Dados mais recentes, do ano de 2015, indicam que o Brasil reciclou 602 mil toneladas de alumínio, sendo líder no segmento de reciclagem de latas desse material, com 97,9\% das embalagens para envase de bebidas recicladas, enquanto o setor de papéis obteve uma taxa de recuperação de 45,7\% (ABRELPE, 2016).

\subsubsection{Aspectos legais e socioeconômicos}

A instituição da Política Nacional de Resíduos Sólidos (PNRS), através da lei No 12.305 de 2 de agosto de 2010, trouxe a gestão integrada de resíduos sólidos para o foco da gestão de resíduos no país. O conceito de gestão integrada diz respeito ao conjunto de ações voltadas à busca de soluções para os resíduos sólidos, envolvendo as dimensões política, econômica, ambiental, cultural e social (BRASIL, 2010). A PNRS reconhece e integra a figura do catador de resíduos reutilizáveis e recicláveis e delega aos municípios e ao Distrito Federal a gestão integrada dos resíduos sólidos gerados nos seus territórios, estando as competências de controle e fiscalização com órgãos federais e estaduais.

Wilson, Velis e Cheeseman (2006) afirmam que milhares de pessoas em países em desenvolvimento dependem da coleta de resíduos recicláveis para sua subsistência. Para a gestão de resíduos desses países, o alcance da melhor forma de trabalhar com esse setor informal tem se tornado um grande desafio, sendo necessárias políticas para melhorias do meio de subsistência, condições de trabalho e da eficiência em reciclagem.

A definição de Aquino, Castilho Junior e Pires (2009) para os integrantes da cadeia produtiva de reciclagem traz: os catadores como responsáveis pela catação, seleção e venda de materiais recicláveis e reaproveitáveis; os intermediários como as empresas formais ou informais e até mesmo associações que compram e vendem esse tipo de material; e as indústrias recicladoras, como organizações que utilizam materiais recicláveis em seus processos de transformação.

Há diversas abordagens ou dimensões possíveis para análise de organizações de catadores. Alencar (2008) apresenta as dimensões de análise Produtiva, Social, Político-Institucional e Ambiental. O foco do presente trabalho está 
inserido na análise da dimensão Produtiva, que avalia essas organizações sobre o ângulo de objetivos que tragam retorno financeiro, mas sem perder características de economia solidária, envolvendo aspectos físico-operacionais e organizacionais determinantes à gestão e operação eficientes (ALENCAR, 2008).

Os estudos mais recentes na literatura abordando o gerenciamento de resíduos sólidos tratam do atendimento às exigências da PNRS na implantação da gestão integrada, através dos planos municipais de gerenciamento de resíduos e com a integração do trabalho de organizações de catadores (LIMA, SILVA, 2013; GUTIERREZ, ZANIN, 2013; OLIVEIRA, GALVÃO JUNIOR, 2016). Não se encontrou na literatura consultada trabalhos que abordassem a dimensão produtiva na atividade de coleta seletiva realizada por organizações de catadores enfocando a análise de seu processo produtivo e capacidade como elaborado nesse trabalho.

\section{ESTUDO DE CASO}

\subsection{Metodologia}

Uma vez que existia contato com uma organização de coleta seletiva disposta a participar do estudo, fornecendo os dados e informações necessários, a primeira etapa do trabalho consistiu na obtenção de dados para a caracterização da organização e análise de seu processo. Para isso, houve a preparação e aplicação de questionário para coleta de dados (MARCONI; LAKATOS, 2006). Esse foi respondido por dois técnicos do Instituto de Tecnologia de Pernambuco (ITEP), que trabalhavam junto à organização. Procurou-se elaborar questões diretas e concisas, sendo a maior parte dessas de múltipla escolha, divididas nos temas: Organização, Estrutura Física, Resíduos Sólidos Recicláveis, Mão de Obra, Processos/Atividades e Informações Adicionais. O questionário foi aplicado por meio eletrônico.

Informações complementares necessárias para um total entendimento e caracterização das atividades da organização foram obtidas através de entrevista semiestruturada (MARCONI; LAKATOS, 2006), realizada nas próprias instalações da organização durante visita técnica. Foram entrevistados a presidente em exercício e um técnico do ITEP, que dá suporte à organização. Através dessas etapas, foi possível compreender a parcela do setor produtivo em que a organização de coleta seletiva está estabelecida e construir o fluxograma do seu processo. 
Deu-se início, então, ao estudo da capacidade da organização, que é definido como primeira etapa para o processo de planejamento e controle da capacidade, a determinação da capacidade total de produção (PAIVA, CARVALHO JUNIOR e FENSTERSEIFER, 2004; SLACK et al., 2008; SLACK, CHAMBERS e JOHNSTON, 2009), obtendo-se informações quantitativas com a medição de níveis agregados de capacidade.

A determinação quantitativa da capacidade foi realizada através de mensuração da produção (Moreira, 2008), com a obtenção de dados do período de um mês (vinte e um dias úteis). A produção foi medida em quilogramas $(\mathrm{kg})$ por dia de trabalho, especificando o tipo de resíduo sólido reciclável coletado. A receita gerada é função direta da produtividade dos associados, em termos de quantidade coletada. Diante desse cenário, fez-se necessário verificar a disponibilidade de RSU recicláveis e reutilizáveis no município e quanto disto é de fato alcançado pela associação. Para isso, estimou-se o quantitativo de RSU que estaria teoricamente disponível, o que foi caracterizado como a oferta à organização.

Para estimar o quantitativo de RSU recicláveis e reutilizáveis gerados no município em estudo, utilizou-se uma estimativa da população atual e dados referentes à composição gravimétrica dos resíduos. A composição gravimétrica expressa percentualmente a presença de cada componente em relação à amostra de resíduo analisada, sendo uma informação de grande importância para compreensão dos resíduos e sua gestão adequada (SOARES, 2011).

Dados quanto a essa variável física dos resíduos sólidos urbanos gerados na área em estudo podem sem visualizados na Tabela 1. É interessante destacar que a porcentagem dos RSU que corresponde a materiais recicláveis na cidade em estudo, Garanhuns, é maior que a de Pernambuco, estado onde ela se localiza. Pode-se inferir desses dados que, em termos de volume de RSU recicláveis gerados, a cidade possui um grande potencial a ser aproveitado pela cadeia produtiva de reciclagem. 
Tabela 1 - Composição gravimétrica dos Resíduos Sólidos gerados na região do estudo

\begin{tabular}{cccc}
\hline \multicolumn{4}{c}{ Composição Gravimétrica - 2010 (\%) } \\
\hline & Garanhuns & Agreste Meridional & Pernambuco \\
Material reciclável & $\mathbf{5 0 , 3 5}$ & $\mathbf{2 2 , 9 9}$ & $\mathbf{2 5 , 7 0}$ \\
Vidro & 0,47 & 1,80 & 2,69 \\
Metal & 3,03 & 2,87 & 3,10 \\
Papel & 15,15 & 7,67 & 8,93 \\
Plástico & 31,70 & 10,64 & 11,04 \\
Matéria Orgânica & $\mathbf{4 1 , 9 6}$ & $\mathbf{6 1 , 2 0}$ & $\mathbf{5 6 , 4 6}$ \\
Rejeitos & $\mathbf{7 , 6 9}$ & $\mathbf{1 5 , 8 1}$ & $\mathbf{1 7 , 8 4}$ \\
Total & $\mathbf{1 0 0 , 0 0}$ & $\mathbf{1 0 0 , 0 0}$ & $\mathbf{1 0 0 , 0 0}$ \\
\hline
\end{tabular}

Fonte: Adaptado de PERNAMBUCO (2012)

Obtidas as informações sobre oferta e capacidade descritas, o estudo ocupou-se em avaliar quanto da oferta de RSU disponível estimada é coletado pela organização e disponibilizado para atender ao mercado, configurado pelas indústrias que demandam RSU recicláveis. A capacidade da organização no atendimento à oferta de RSU disponíveis é convertida, consequentemente, no atendimento de uma parcela maior ou menor da demanda por esses materiais.

\section{2 Área de estudo}

O estudo foi realizado em uma associação de catadores de material reciclável instalada no município pernambucano de Garanhuns, a Associação dos Catadores de Papel, Papelão e Material Reaproveitável de Garanhuns - Nova Vida (ASNOV). Garanhuns é um município da região Agreste Meridional do estado de Pernambuco que possui uma população de 129.408 habitantes, de acordo com o último censo de 2010 (IBGE, 2016), e uma área territorial de $472,46 \mathrm{~km}^{2}$, tendo cerca de $80,0 \%$ dos habitantes concentrados na área urbana. O município está localizado no Planalto da Borborema, distante $230 \mathrm{~km}$ da capital do estado, Recife, e destaca-se no Agreste Meridional por atividades na área comercial e de turismo e lazer e na produção leiteira. A Figura 3 traz um mapa de Pernambuco com o município de Garanhuns em destaque. 
Figura 3 - Mapa estado de Pernambuco, município de Garanhuns no destaque

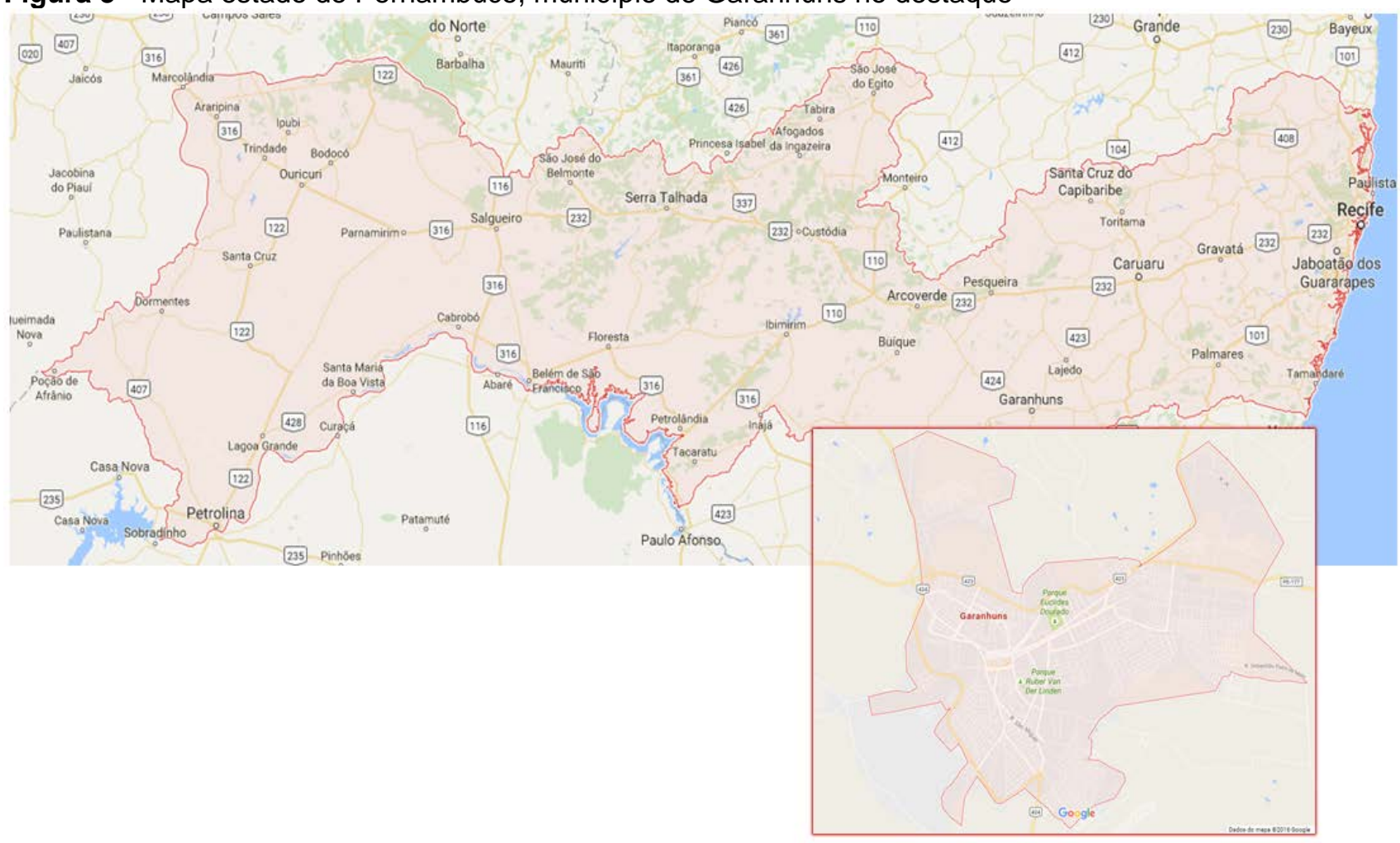

Fonte: Google Maps ${ }^{\circledR}, 2016$

Podem ser visualizados, nas Tabelas 2 e 3 a seguir, valores da geração de resíduos sólidos per capita no município de estudo e sua região de desenvolvimento no estado de Pernambuco, bem como a produção total atual e a projetada para alguns anos. A quantificação apresentada diz respeito aos RSU, tendo sido avaliadas as produções domiciliares, comerciais e a produção de resíduos públicos, referentes aos serviços de limpeza de vias e logradouros, capinação e podas (PERNAMBUCO, 2012). A geração per capita média de resíduos sólidos para estado de Pernambuco como um todo, de acordo com seu Plano Estadual de Resíduos Sólidos, é de 1,05 kg/habitante por dia, o que resultaria numa produção total de 4 milhões de toneladas de RSU por ano. 
Tabela 2 - Taxa de Geração per capita e Produção de Resíduos Sólidos por região e municípios para o estado de Pernambuco

\begin{tabular}{ccccccc}
\hline $\begin{array}{c}\text { Média por Região de } \\
\text { Desenvolvimento e Município }\end{array}$ & $\begin{array}{c}\text { Taxa de } \\
\text { geração } \\
\text { per capita } \\
\text { Kg/habitante/dia }\end{array}$ & População 2012 & \multicolumn{3}{c}{ Produção de Resíduos Sólidos } \\
\cline { 4 - 7 } Agreste Meridional & 1,38 & $651.114,00$ & 797,97 & $23.939,15$ & $291.259,64$ \\
Garanhums & 1,27 & $131.645,00$ & 167,19 & $5.015,67$ & $61.024,04$ \\
\hline
\end{tabular}

Fonte: Adaptado de PERNAMBUCO (2012)

Tabela 3 - Projeções da Produção de Resíduos Sólidos por região e municípios para o estado de Pernambuco

\begin{tabular}{|c|c|c|c|c|c|c|}
\hline \multirow{2}{*}{$\begin{array}{c}\text { Média por Região } \\
\text { de Desenvolvimento e } \\
\text { Município }\end{array}$} & \multicolumn{6}{|c|}{ Agreste Meridional } \\
\hline & 2014 & 2016 & 2020 & 2024 & 2028 & 2032 \\
\hline Projeção da população & $660.501,00$ & $667.006,00$ & $678.400,00$ & $687.648,00$ & $696.054,00$ & $703.619,00$ \\
\hline \multirow{3}{*}{$\begin{array}{l}\text { Projeção da produção } \\
\text { de resíduos sólidos } \\
\text { (t/ano) }\end{array}$} & $295.064,07$ & $297.695,56$ & $302.305,37$ & $306.046,45$ & $309.447,06$ & $312.507,20$ \\
\hline & \multicolumn{6}{|c|}{ Garanhuns } \\
\hline & 2014 & 2016 & 2020 & 2024 & 2028 & 2032 \\
\hline Projeção da população & $133.882,00$ & $135.384,00$ & $138.015,00$ & $140.150,00$ & $142.090,00$ & $143.836,00$ \\
\hline $\begin{array}{c}\text { Projeção da produção } \\
\text { de resíduos sólidos } \\
\text { (t/ano) }\end{array}$ & $62.061,00$ & $62.757,25$ & $63.976,85$ & $64.966,38$ & $65.865,82$ & $66.675,18$ \\
\hline
\end{tabular}

Fonte: Adaptado de PERNAMBUCO (2012)

\section{RESULTADOS E DISCUSSÃO}

\subsection{Caracterização da organização do estudo de caso}

A ASNOV é a organização responsável pela coleta seletiva no município de Garanhuns, Pernambuco. Ela não possui fins lucrativos e a receita obtida de suas atividades é empregada para pagamento de despesas básicas de manutenção e remuneração mensal dos associados. A receita depende diretamente do volume produzido pelos associados e pode variar consideravelmente em função de sua frequência. Quando o estudo foi realizado, o número de associados desempenhando atividades na organização encontrava-se constante a alguns meses.

Conforme obtido através da aplicação do questionário, a ASNOV conta com 25 (vinte e cinco) trabalhadores associados, sendo 9 (nove) homens e 16 (dezesseis) mulheres. Desses, 21 (vinte e um) estavam envolvidos diretamente nas atividades de catação quando da coleta dos dados. A faixa etária dos associados, de 
25 a 69 anos, é bastante ampla. A associação realiza suas atividades de segunda a sexta, nos turnos da manhã e tarde, e é obrigatório o uso de uniformes e de Equipamentos de Proteção Individual (EPI) - luvas adequadas, sapatos de segurança e óculos de proteção - durante essas atividades.

Os cargos existentes são de coletor, secretário, tesoureiro, vice-presidente e presidente. Há ainda um conselho fiscal, constituído por três associados, e um técnico local do município de Garanhuns em tempo permanente. É importante destacar que, ainda que associados desempenhem funções diferentes, a remuneração mensal é igual para todos. Essa é inferior a um salário mínimo, estando a média mensal em $\mathrm{R} \$ 450,00$ (quatrocentos e cinquenta). O programa Recicla Pernambuco (Recicla - PE), executado pelo Instituto de Tecnologia de Pernambuco (ITEP), que oferecia suporte técnico com equipe multidisciplinar, esteve presente até junho de 2016.

A ASNOV funciona em instalações próprias, em espaço de aproximadamente $800 \mathrm{~m}^{2}$ (oitocentos metros quadrados), contando com galpão, espaço para triagem dos materiais coletados, sala de administração, banheiros e uma pequena copa. $\mathrm{Na}$ Figura 4, pode-se visualizar o galpão existente nas instalações.

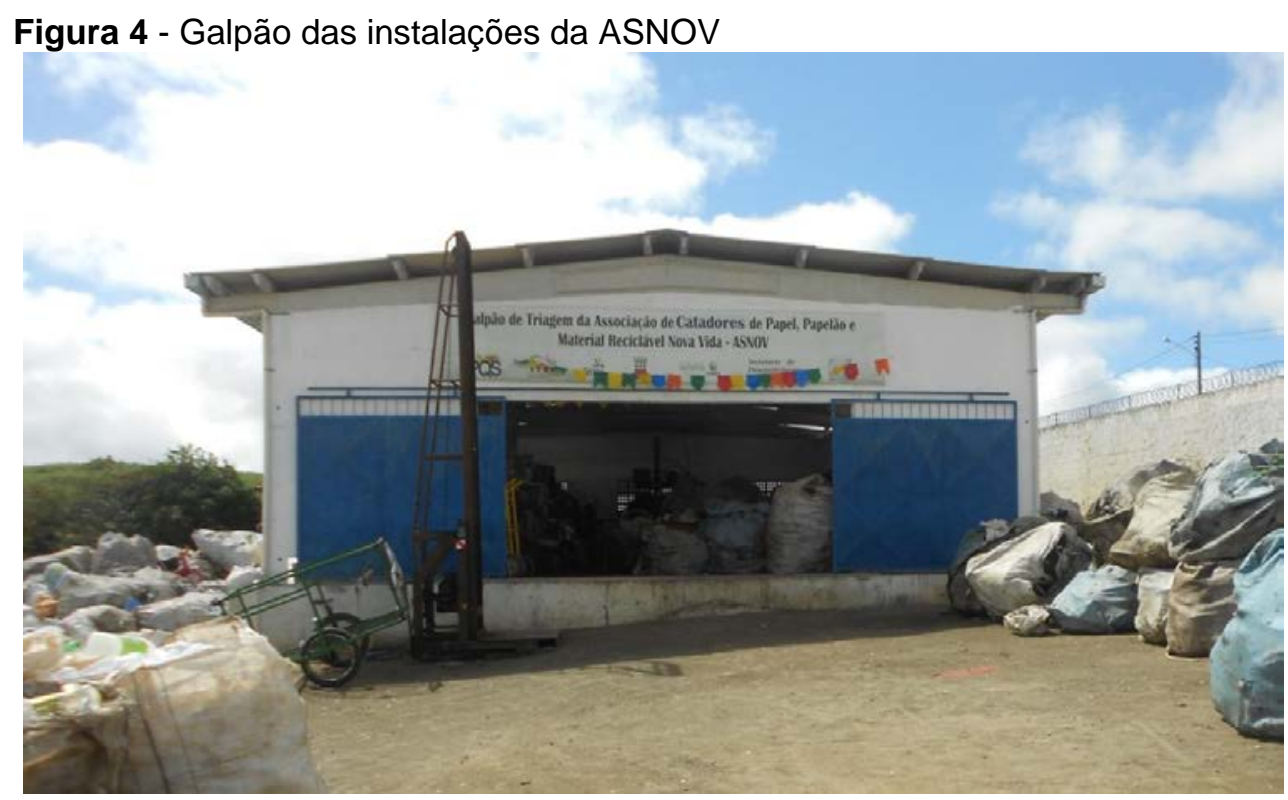

Fonte: Os autores (2016)

Os resíduos coletados pela organização são variados e, em sua maioria, chegam à organização sem separação alguma por tipo de material, de modo que é necessária uma operação inicial de triagem. Os resíduos sólidos recicláveis coletados pela ASNOV encontram-se listados no Quadro 1. 
Quadro 1 - Listagem dos tipos de resíduos sólidos recicláveis coletados pela ASNOV

\begin{tabular}{|c|c|}
\hline \multicolumn{2}{|c|}{ Resíduos sólidos recicláveis coletados } \\
\hline Papelão & Sacolas e filmes plásticos \\
\hline Papel misto & Latas de alumínio \\
\hline Papel jornal & Tampas de garrada PET \\
\hline Politereftalato de Etileno (PET) & Ferro \\
\hline Polietileno de Alta Densidade (PEAD) & Vidro \\
\hline Policloreto de Vinila (PVC), & Cobre \\
\hline $\begin{array}{c}\text { Cacareco (constituído basicamente de } \\
\text { restos de objetos como bacias e baldes) }\end{array}$ \\
\hline
\end{tabular}

Fonte: Os autores (2017)

As atividades desempenhadas pela ASNOV encontram-se na base do setor produtivo de reciclagem. A coleta seletiva é o que permite a disponibilidade de resíduos sólidos recicláveis ou reutilizáveis para as indústrias que os empregam como matéria prima. Uma representação simplificada da parcela do setor produtivo de reciclagem significante para o escopo desse estudo é apresentada na Figura 5, na qual é possível identificar a posição de catadores e associações, como a ASNOV, nessa cadeia produtiva. A associação precisa gerenciar a oferta disponível de resíduos sólidos vinda das fontes geradoras e a demanda originária das indústrias que adquirem esses materiais, absorvendo a produção de material coletado.

Figura 5 - Representação simplificada de parcela da cadeia produtiva do setor de reciclagem em que a ASNOV, como associação de catadores, está inserida

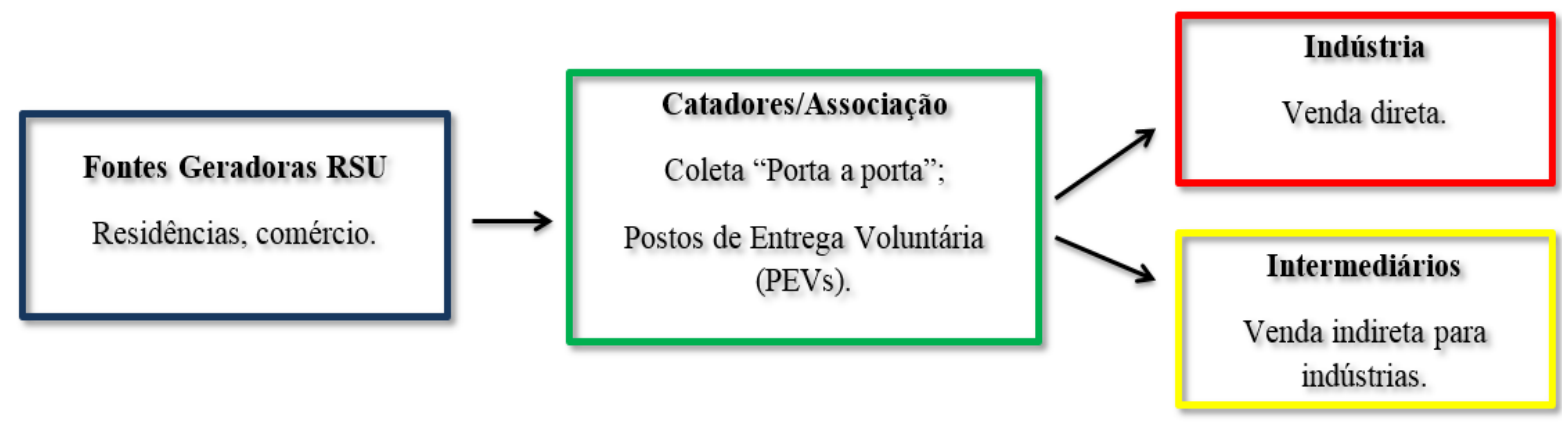

Fonte: Os autores (2017)

As fontes geradoras de RSU são as localidades de origem dos resíduos e onde os catadores da ASNOV obtêm esses materiais. São residências integradas ao sistema de coleta semanal da organização, estabelecimentos comerciais e indústrias 
que entregam seus resíduos sólidos recicláveis ou reutilizáveis à associação, instituições públicas e privadas.

A coleta dos resíduos sólidos nesses locais é realizada pela associação através das modalidades 'Porta a Porta' e Postos de Entrega Voluntária (PEVs). A primeira situação, como a denominação indica, consiste em coletar os materiais nas portas das residências e estabelecimentos que fazem parte da rede de coleta. As residências integradas à coleta seletiva utilizam um adesivo na fachada, que as identifica e assinala os dias da semana em que os catadores da associação realizam a coleta naquele local. Uma imagem desse adesivo é apresentada na Figura 6.

Figura 6 - Adesivo identificador para residência participante da coleta seletiva

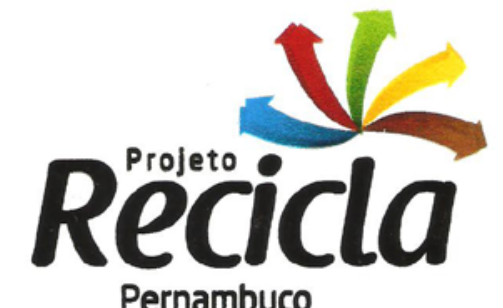

\section{Eu faço coleta seletiva}

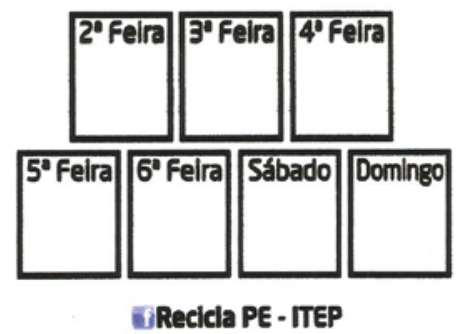

Fonte: Material de divulgação da ASNOV (2016)

A modalidade de PEVs é utilizada em locais de grande fluxo de pessoas, instalando-se um recipiente coletor no qual a própria população pode depositar resíduos sólidos recicláveis. Um exemplo é o emprego de PEVs durante o Festival de Inverno de Garanhuns, evento anual realizado no mês de julho pelo município e que atrai turistas de todo o país.

A demanda por resíduos sólidos recicláveis e reutilizáveis que a ASNOV se propõe a atender é formada por indústrias recicladoras e/ou que adquirem esses materiais para empregar como parte da matéria-prima de seus produtos. Os resíduos coletados podem chegar a esse mercado consumidor pelo que se denomina vias direta e indireta.

Revista Produção Online. Florianópolis, SC, v. 18, n. 4, p. 1344-1373, 2018. 
$\mathrm{Na}$ primeira situação, os materiais são comercializados diretamente às indústrias, sendo necessário atingir certos requisitos estabelecidos por essas, como volume e qualidade do material comercializado. A via indireta é utilizada quando não se pode atender aos requisitos das indústrias e diz respeito às vendas em menor quantidade para os chamados intermediários, negócios que compram resíduos sólidos recicláveis e reutilizáveis de catadores e/ou organizações de catadores, agregando maiores volumes desses resíduos e os repassam às indústrias com alguma margem de lucro.

De acordo com os responsáveis pela administração da ASNOV entrevistados para este trabalho, o preço obtido para venda dos materiais aos intermediários é sempre consideravelmente menor do que o obtido para venda direta às indústrias. Essa situação foi exemplificada pelos participantes da entrevista através do papelão, que tem um preço cerca de $40 \%$ inferior quando vendido para intermediários.

\subsection{Análise do processo produtivo}

O fluxograma é o primeiro resultado da análise do processo de produção da organização e pode ser observado na Figura 7.

As operações, ou atividades produtivas, da ASNOV começam com a coleta dos RSU recicláveis e reutilizáveis, através do Porta a Porta e/ou PEVs. Essa etapa, externa às instalações da organização, acontece no turno da manhã. Após a coleta pelo trajeto programado para o dia, os materiais são reunidos e transportados às instalações em caminhão. Na associação, os materiais passam, durante o turno da tarde, pelas atividades de triagem, fardagem e pesagem, deixando-os preparados para a comercialização. Nas Figuras 8 e 9, pode-se visualizar, respectivamente, operadores prensando material reciclável na operação de fardagem e fardos já prontos para venda armazenados em galpão da organização. 
Figura 7 - Fluxograma da ASNOV

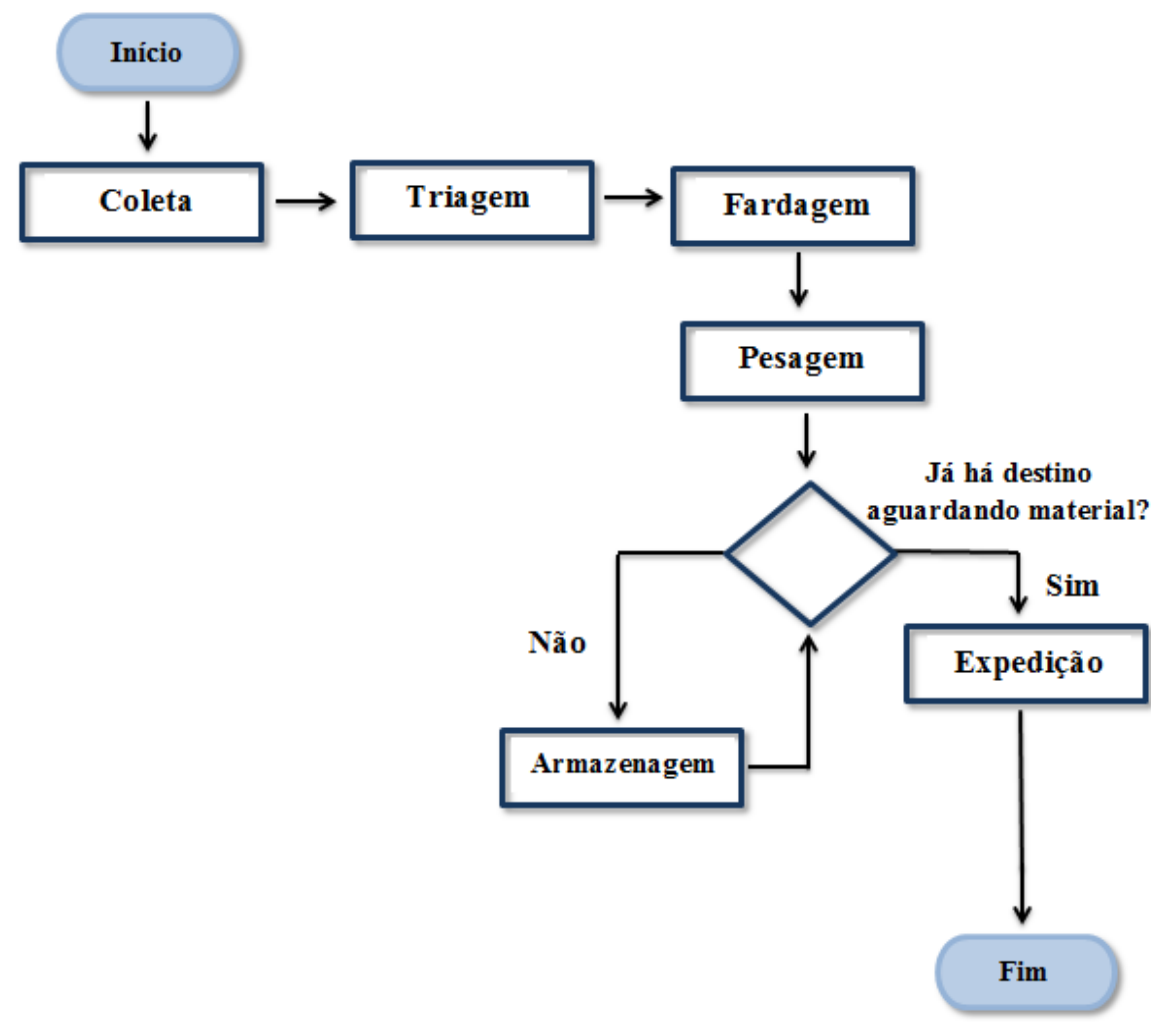

Fonte: Os autores (2017)

Figura 8 - Operação de prensagem de material reciclável coletado para constituição de fardo

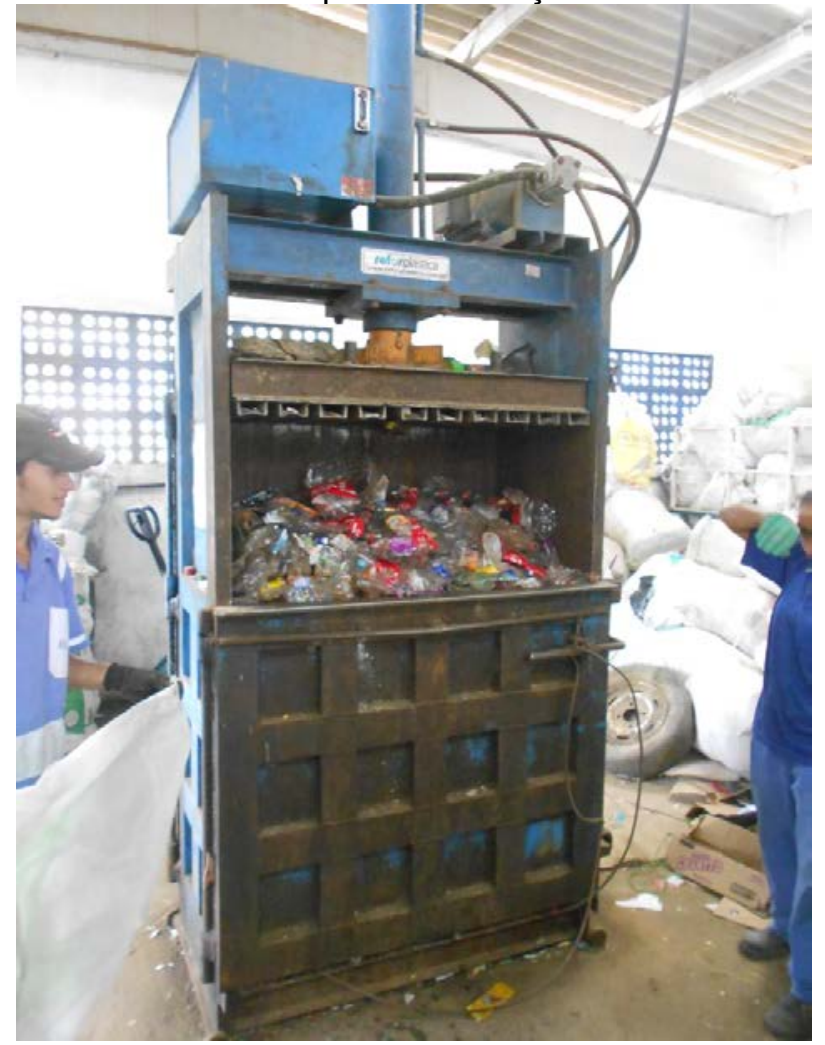

Fonte: Os autores (2016)

Revista Produção Online. Florianópolis, SC, v. 18, n. 4, p. 1344-1373, 2018. 
Figura 9 - Fardos de material reciclável prontos para venda armazenados no galpão da ASNOV

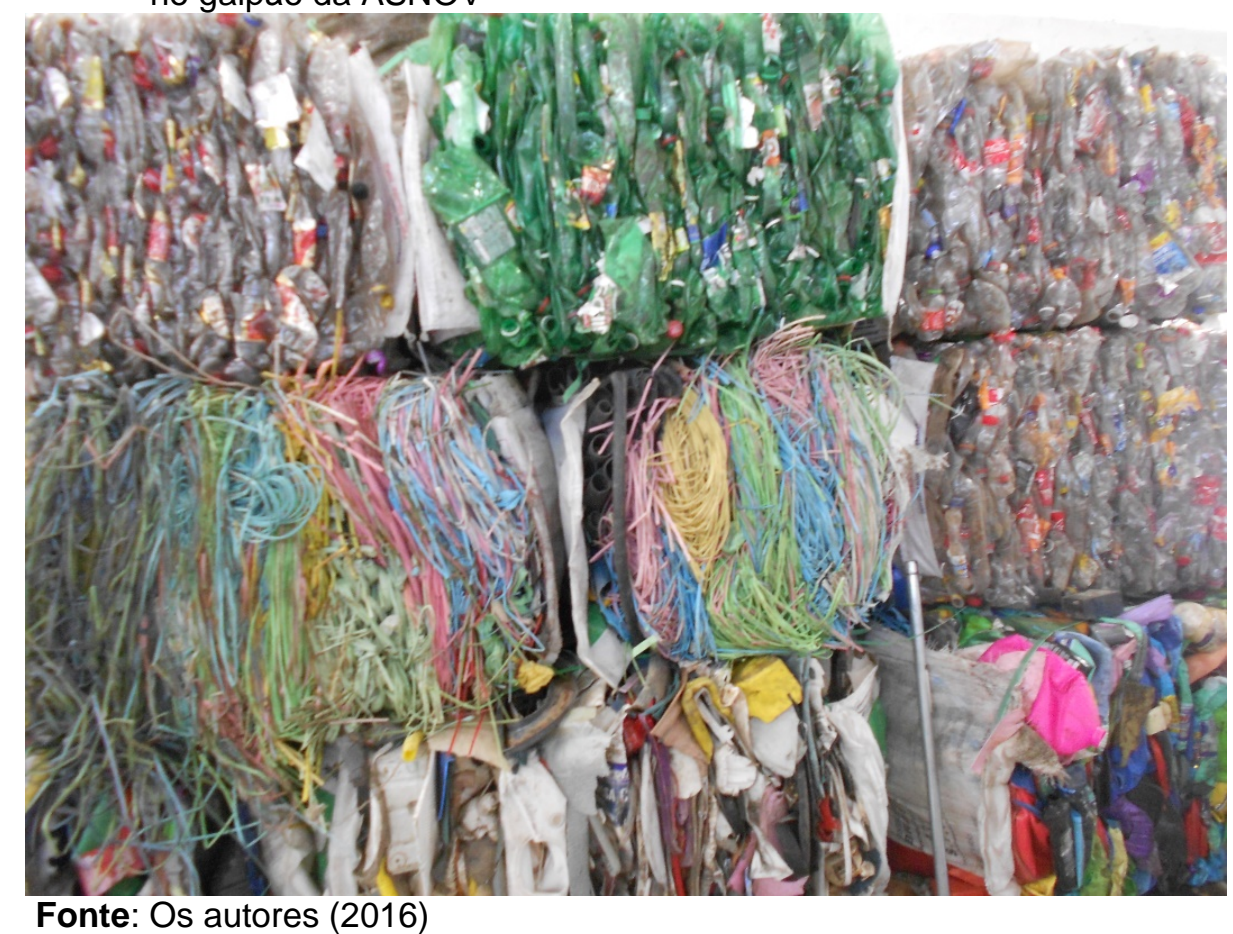

Na triagem, realiza-se uma separação completa dos materiais e a eliminação daqueles impróprios para venda que, porventura, estejam misturados à coleta. $A$ fardagem é a constituição dos fardos de cada material. Agrupa-se a quantidade adequada à venda e, então, o material é prensado. As últimas atividades são a pesagem dos fardos e expedição dos materiais com destino aos compradores. Caso os fardos constituídos e pesados ainda não tenham destino definido, ficam armazenados até o momento da venda, quando há então a expedição.

Os resíduos sólidos coletados representam os insumos, ou input, desse processo produtivo, constituído pelas operações de coleta até expedição dos fardos, e o produto, ou output, são os fardos de resíduos sólidos recicláveis comercializados pelas vias direta ou indireta.

\subsection{Avaliação da capacidade produtiva}

A receita da organização de coleta seletiva em estudo é função direta da produtividade dos seus associados, em termos de quantidade coletada. A capacidade desse processo de coleta precisa ser avaliada antes de qualquer tomada de decisão para emprego de melhorias (STAUDT; COELHO; GONÇALVES, 2011; ALMEIDA; ROMANZINI; WERNER, 2016). 
Dentre os RSU gerados no município, constituídos de resíduos sólidos domiciliares e de limpeza urbana, apenas uma parcela é de interesse da organização e/ou é coletada por esta. Por essa razão, fez-se uso da caracterização gravimétrica, conforme apresentada na Tabela 1 na Metodologia.

Para um quantitativo atualizado da população de Garanhuns, utilizaram-se dados populacionais estimados pelo IBGE. A estimativa para o ano de 2016 foi de 137.810 mil habitantes (IBGE, 2016). Os dados referentes à geração per capita diária de RSU e a estimativa populacional foram multiplicados pela quantidade de dias no mês e, então, calculou-se quanto do valor obtido representava a porcentagem de RSU recicláveis. Os resultados obtidos segundo as considerações apresentadas podem ser vistos na Tabela 4 abaixo.

\begin{tabular}{|c|c|}
\hline \multicolumn{2}{|c|}{ RSU em Garanhuns - oferta estimada } \\
\hline População estimada (milhares) & $137.810,00$ \\
\hline $\begin{array}{c}\text { Taxa de geração per capita } \\
\text { (kg/hab./dia) }\end{array}$ & 1,27 \\
\hline Quantidade diária (t) & 175,019 \\
\hline Quantidade mensal (t) & $5.250,561$ \\
\hline Porcentagem Material Reciclável & $50,35 \%$ \\
\hline $\begin{array}{c}\text { Quantidade mensal material } \\
\text { reciclável (t) }\end{array}$ & $2.643,657$ \\
\hline
\end{tabular}

Fonte: Os autores (2017)

O valor teórico para oferta de RSU recicláveis obtido para o município de Garanhuns, de 2643,657 toneladas mensais, pode ser considerado em sua totalidade, uma vez que a associação atende todos os bairros da zona urbana e mais 2 (dois) distritos da zona rural. O município de Garanhuns é dividido em sede, que por sua vez é subdividida em 12 (doze) bairros, e em 3 (três) distritos, Iratama, Miracica e São Pedro (GARANHUNS, 2016).

Os dados de produção da ASNOV foram obtidos para um período de um mês (vinte e um dias úteis). O gráfico na Figura 10 apresenta dados da capacidade produtiva agregada, onde não há separação por tipo de material coletado. Obtevese, no intervalo estudado, uma produção mensal de 22,779 toneladas de material reciclável coletado. Esse valor pode ser entendido como a capacidade operacional 
realizada pela organização no período, pois é o valor da capacidade efetiva tendo sido subtraídas possíveis perdas planejadas e não planejadas do processo no período considerado (SLACK; CHAMBERS; JOHNSTON, 2009), devidas a funcionários faltosos ou ao tempo perdido em manutenção ou em trocas de turnos, por exemplo.

Figura 10 - Produção diária (em toneladas) da ASNOV pelo período de um mês (21 dias úteis)

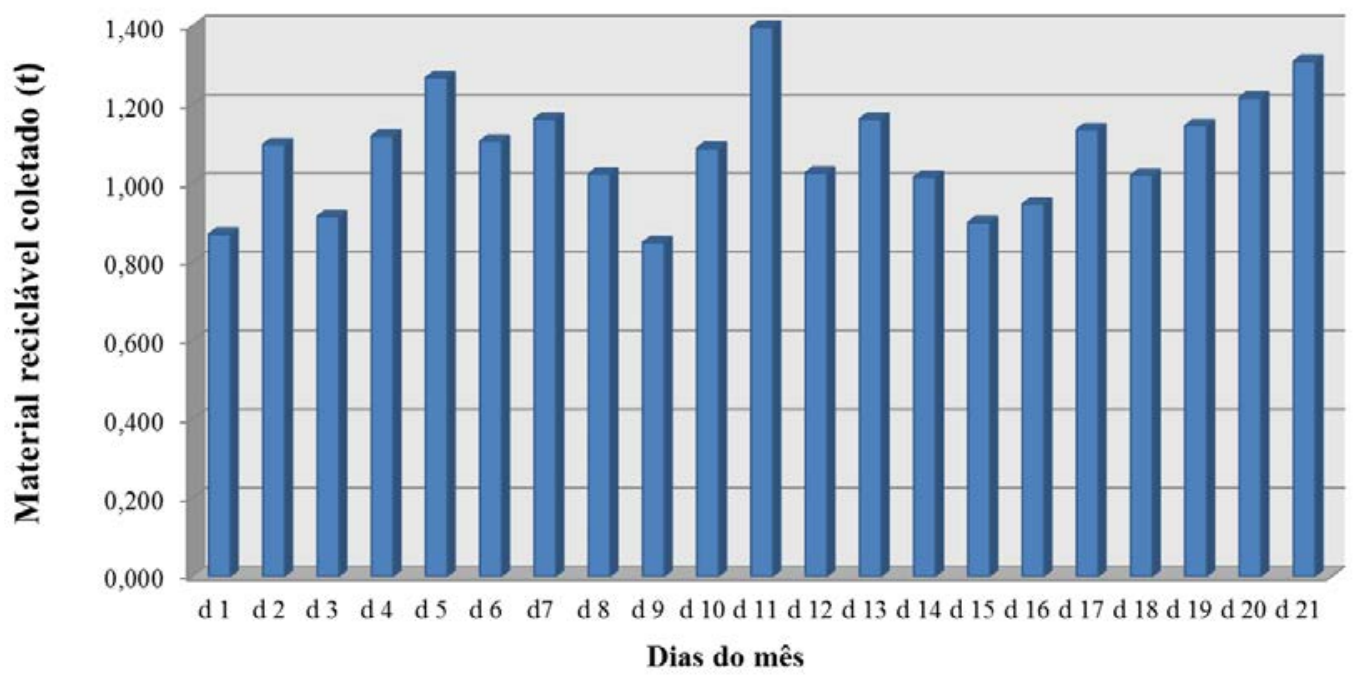

Fonte: Os autores (2017)

Figura 11 - Contribuição percentual de cada tipo de material coletado para o total

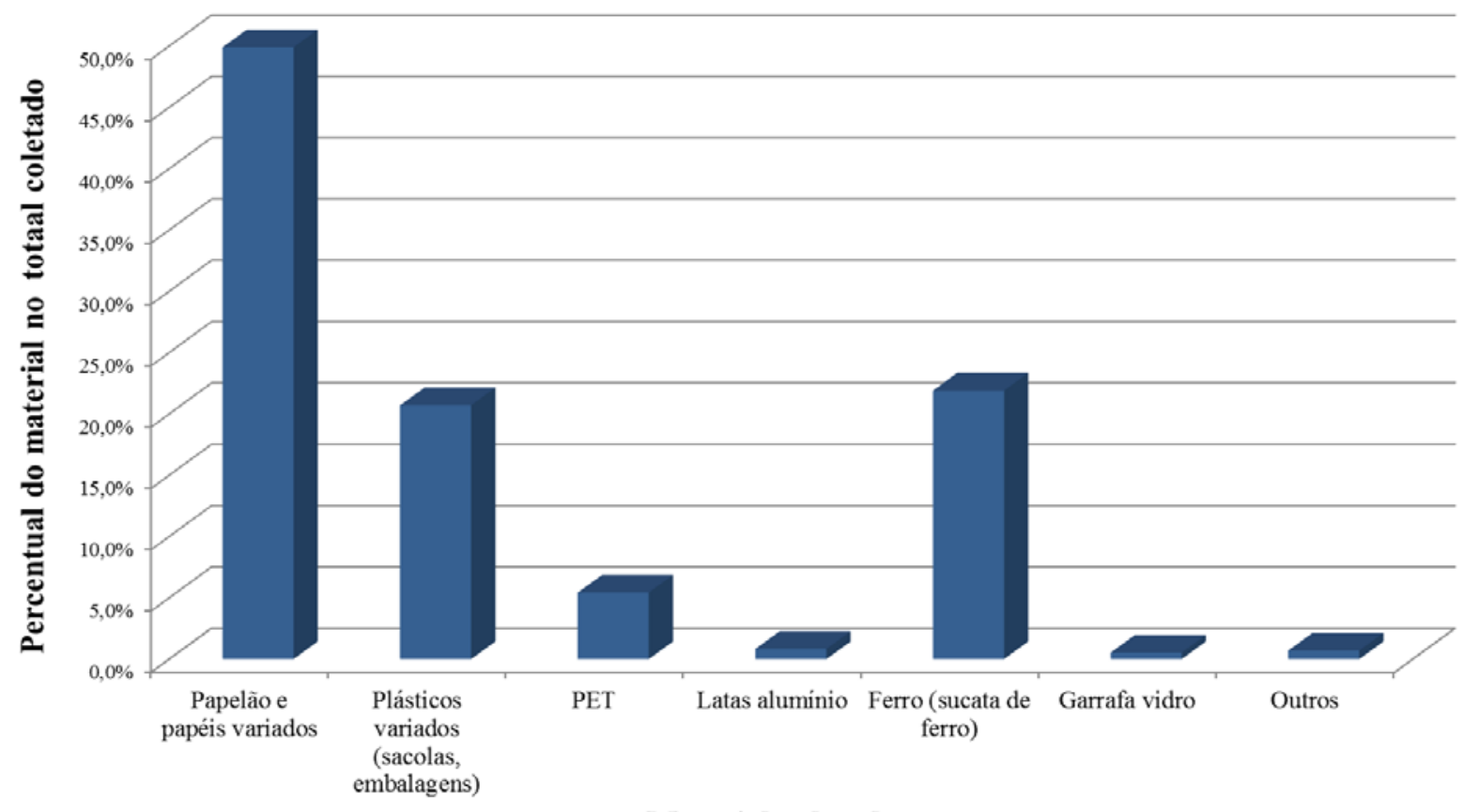

Fonte: Os autores (2017) 
A contribuição de cada tipo de material coletado para o total produzido é apresentada de forma percentual no gráfico da Figura 11. Papelão e papéis variados respondem por $49,90 \%$ do total dos materiais recicláveis coletados, seguido por plásticos diversos (como plástico leitoso branco e o PVC), com 20,70\%, pela sucata de ferro, com 21,91\%, e pelo PET, 5,43\%, sendo esses os maiores percentuais de contribuição.

Os valores percentuais maiores para papel, papelão e plásticos diversos podem ser explicados pela presença em maior quantidade desses materiais, largamente utilizados em embalagens, por exemplo, nos resíduos gerados por residências e estabelecimentos comerciais. Além desse fator, percebe-se sua grande recepção pelo mercado consumidor de intermediários e indústrias recicladoras. Isso levaria a organização a reforçar a coleta desses materiais, em detrimento de outros, a exemplo do vidro, que passou um período praticamente sem ser coletado pela organização devido a alterações na demanda da indústria que o adquiria.

Obtiveram-se ainda dados da produção mensal da associação para 4 (quatro) meses anteriores ao período de realização do trabalho com o objetivo de observar se o volume de produção vem mantendo-se dentro de um valor médio ou se há muita variação. Esses dados podem ser visualizados na Figura 12. São vistas variações entre os meses considerados para as quais uma possível justificativa é a flutuação na frequência dos colaboradores atuantes na organização conforme comentado na seção 4.1 Caracterização da organização do estudo de caso. Alguns deles costumam, inclusive, não comparecer sem aviso, segundo informações obtidas junto aos entrevistados, retornando apenas quando precisam agregar a sua renda.

Para efeito da análise proposta neste estudo, calculou-se um valor médio para a capacidade operacional agregada da associação. Foi realizado um cálculo de média aritmética simples com os dados da capacidade realizada desses 4 (quatro) meses e do mês de realização do estudo, totalizando, 5 (cinco) meses.

O valor médio obtido para a capacidade foi de 18,7584 toneladas por mês. A comparação desse valor de capacidade operacional com a oferta teórica obtida de RSU demonstra que, das 2.643,657 toneladas mensais de RSU recicláveis geradas no município, a associação coleta em média apenas 18,7584 toneladas. 
Figura 12 - Dados da produção mensal nos quatro meses anteriores ao estudo e no mês em estudo

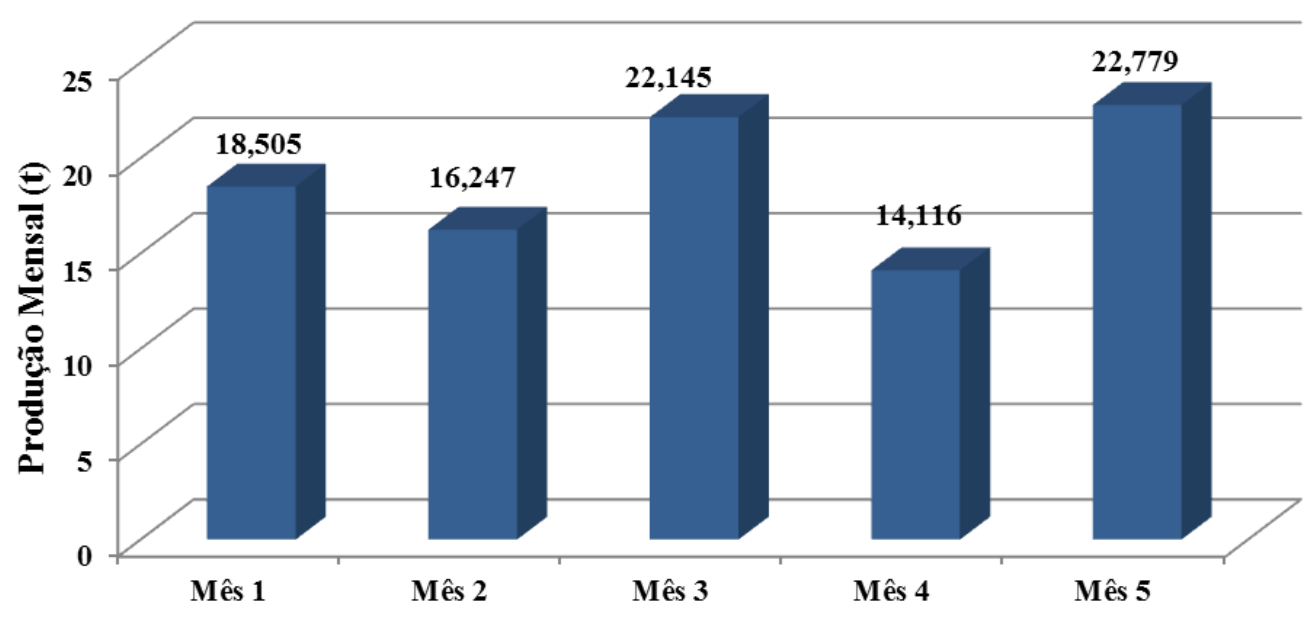

Fonte: Os autores (2017)

Esse valor diz respeito a um alcance médio de $0,709 \%$ do total de RSU recicláveis gerados no município. É um volume bastante reduzido, comparado ao potencial de RSU gerados e, teoricamente, disponível para coleta. Porém, numa comparação com a cidade de São Paulo, a maior do país e que conta com atividades de coleta seletiva bem mais consistentes, esse valor pode ser visto de forma positiva. Na cidade de São Paulo, apenas 1,9\% dos resíduos sólidos é absorvido por ações de coleta seletiva (PASCHOALIN FILHO et al., 2014). Assim, o valor de $0,709 \%$, para uma cidade que conta apenas com a organização em análise neste estudo para a realização de coleta seletiva, demonstra, consideradas as proporcionalidades, um alcance relevante, ainda que esse precise e deva ser expandido.

A partir desse resultado da capacidade operacional realizada atual, a organização, objetivando ampliar o volume alcançado e, consequentemente, sua receita, deve avaliar se isso pode ser alcançado através de um melhor gerenciamento do processo produtivo ou se só será possível a partir de ações, como ampliação das instalações, contratação de mão de obra e novos equipamentos. Essas decisões são parte da etapa de identificação de políticas alternativas de capacidade, no processo de planejamento e controle da capacidade (PAIVA, CARVALHO JUNIOR E FENSTERSEIFER, 2004; SLACK; CHAMBERS; JOHNSTON, 2009). 
As decisões para o planejamento e controle da capacidade nessa situação necessitam de um estudo da capacidade, no qual se detalhe cada etapa do processo produtivo. Esse detalhamento permite, por exemplo, identificar se há ineficiências, recursos ociosos ou subutilizados, ou ainda operando em sua capacidade máxima (STAUDT, COELHO, GONÇALVES, 2011). Essa avaliação é seguramente recomendada como estudo futuro para a organização. Informações iniciais quanto aos recursos organizacionais disponíveis nas etapas do processo produtivo, que determinam a capacidade de operação da organização, foram ainda identificadas neste trabalho, através do questionário e visita técnica, e são apresentadas na Figura 13.

Figura 13 - Recursos organizacionais disponíveis em cada etapa do processo produtivo

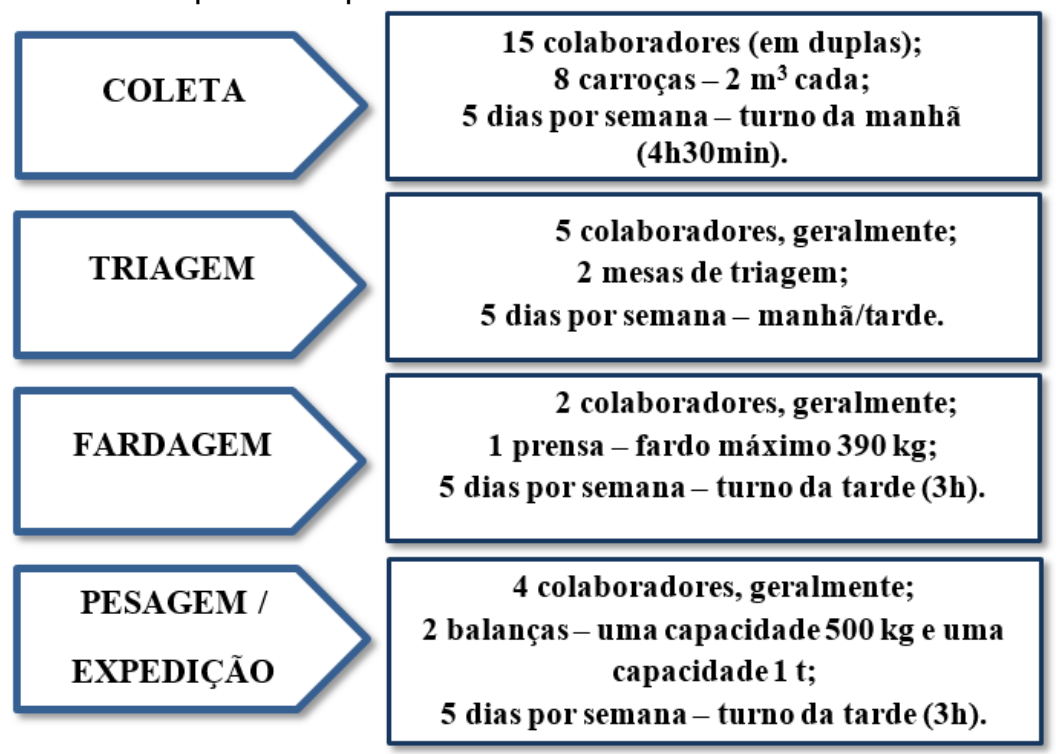

Fonte: Os autores (2017)

\section{CONSIDERAÇÕES FINAIS}

A ASNOV possui papel relevante sendo a única organização que realiza coleta seletiva no seu município, com uma capacidade de captação de RSU de 18,7584 toneladas mensais, em média. Ela contribui para a melhor destinação dos RSU recicláveis e reutilizáveis, reduzindo o volume destinado ao aterro, mesmo que absorva apenas uma pequena parcela da oferta desses materiais no município. A organização é ainda geradora de emprego e renda para cerca de 20 famílias.

Avaliar a ASNOV sob a ótica produtiva trouxe uma nova perspectiva às atividades desenvolvidas pela organização, sendo o passo inicial para aprimorar a Revista Produção Online. Florianópolis, SC, v. 18, n. 4, p. 1344-1373, 2018. 
gestão de seu processo. O fluxograma do processo produtivo e análise da capacidade operacional, com as atividades e recursos empregados, inserem na organização uma visão mais clara de seu processo, que poderá ser empregada em estudos mais aprofundados para seu planejamento produtivo.

Recomenda-se, para estudos futuros, uma avaliação mais detalhada da capacidade organizacional, considerando as atividades individualmente e avaliando, por exemplo, se há subutilização ou recursos operando em capacidade máxima, identificando-se alternativas mais adequadas para a melhor utilização da capacidade. Isso é relevante, pois há uma oferta potencial de RSU e intermediários e indústrias que representam uma demanda capaz de absorver a produção da organização. O melhor gerenciamento do processo produtivo pode fazer, por exemplo, com que a organização alcance a venda direta às indústrias.

Aconselha-se, também, dadas as características do contexto social e ambiental de atuação da organização, o fortalecimento da participação da população e organizações locais no sistema de coleta seletiva. Destaca-se que o poder público municipal, diante de uma atividade de alto impacto, possa apoiar a organização de forma mais contundente, a partir da disponibilização de infraestrutura adequada e apoio financeiro capaz de garantir a sua sustentabilidade.

A análise realizada neste estudo apresentou-se desafiadora devido à ausência de informações apuradas quanto à capacidade do processo e de dados como registros históricos de demanda atendida. Entretanto essa é uma característica que pode ser vista como relativamente comum em organizações como a que foi alvo da pesquisa, o que reforça a importância da inserção de conhecimento técnico nesses ambientes, possibilitando o aprimoramento de sua gestão e processos.

\section{REFERÊNCIAS}

AKSIN, O.Zeynep et al. Flexibility Structure and Capacity Design with Human Resource Considerations. Production And Operations Management, [s.I.], v. 24, n. 7, p.1086-1100, 26 jan. 2015.

ALENCAR, Bertrand Sampaio de. Emergência de novos atores no desenvolvimento sustentável: a contribuição dos catadores de materiais recicláveis no Brasil. 2008. 262 f. Tese (Doutorado) - Curso de Pós-graduação Desenvolvimento Urbano, Universidade Federal de Pernambuco, Recife, 2008. 
ALENCAR, Bertrand Sampaio de; SANTOS, Romenia Maria Moura. Avaliação do Modelo de Coleta Seletiva no Município de Garanhuns/PE, Brasil. In: ENCONTRO PERNAMBUCANO DE RESÍDUOS SÓLIDOS, 2. 2013, Recife. Anais. Recife: UFRPE, 2013.

ALMEIDA, Rodrigo Pessotto; ROMANZINI, Fernanda; WERNER, Liane. Planejamento da capacidade de produção na indústria plástica: uma abordagem baseada em previsão de demanda e níveis de capacidade. Revista Produção Online, [s.I.], v. 16, n. 3, p.1033-1057, 15 set. 2016.

ANTUNES, Junico et al. Sistemas de Produção: Conceitos e práticas para projeto e gestão da produção enxuta. Porto Alegre: Bookman, 2008.

AQUINO, Israel Fernandes de; CASTILHO JUNIOR, Armando Borges de; PIRES, Thyrza Schlichting de Lorenzi. A organização em rede dos catadores de materiais recicláveis na cadeia produtiva reversa de pós-consumo da região da grande Florianópolis: uma alternativa de agregação de valor. Gestão \& Produção, São Carlos, v. 1, n. 16, p.15-24, jan-mar. 2009.

ASSOCIAÇÃO BRASILEIRA DE EMPRESAS DE LIMPEZA PÚBLICA E RESÍDUOS ESPECIAIS - ABRELPE. Panorama dos Resíduos Sólidos no Brasil 2016. 14. ed. São Paulo: Abrelpe, 2016. Disponível em:

<http://www.abrelpe.org.br/Panorama/panorama2016.pdf>. Acesso em: 22 out. 2017.

ASSOCIAÇÃO BRASILEIRA DE EMPRESAS DE LIMPEZA PÚBLICA E RESÍDUOS ESPECIAIS - ABRELPE. Panorama dos Resíduos Sólidos no Brasil 2014. 12. ed. São Paulo, 2014. Disponível em: http://www.abrelpe.org.br/Panorama/panorama2014.pdf . Acesso em: 25 ago. 2016.

BARNES, Ralph Mosser. Estudo de movimentos e de tempos: projeto e medida do trabalho. 6. ed. São Paulo: Edgard Blücher Ltda, 1977.

BRASIL. Governo Federal. Ministério do Meio Ambiente. PLANO NACIONAL DE RESÍDUOS SÓLIDOS: Versão Preliminar para Consulta Pública. Brasília, 2011. Disponível em: http://www.mma.gov.br/estruturas/253/ publicacao/253 publicacao02022012041757.pdf . Acesso em: 13 ago. 2016.

BRASIL, Lei 12.305, de 2 de agosto de 2010. Institui a Política Nacional de Resíduos Sólidos; altera a Lei no 9.605, de 12 de fevereiro de 1998 e dá outras providências. Lex: coletânea de legislação e jurisprudência: legislação federal e marginalia, São Paulo, v. 74, p. 950-971, ago. 2010.

BUQUE, Lina Ivette Bartolomeu; RIBEIRO, Helena. Panorama da coleta seletiva com catadores no município de Maputo, Moçambique: desafıos e perspectivas. Saúde e Sociedade, [s.I.], v. 24, n. 1, p.298-307, mar. 2015. COMPROMISSO EMPRESARIAL PARA RECICLAGEM - CEMPRE (Brasil). CEMPRE Review 2015. São Paulo: Cempre, 2015.

GOMES, Aline Pimentel et al. Diagnóstico do processo de coleta e comercialização de recicláveis realizado por catadores na cidade de Passo Fundo/RS (BRASIL). Holos Environment, [s. L.], v. 12, n. 2, p.201-214, jan. 2012.

GOOGLE MAPS. [Mapa Pernambuco e Garanhuns]. 2016. Disponível em: https://www.google.com.br/maps/place/Pernambuco/@-8.3661457,40.3277002,7z/data=!3m1!4b1!4m5!3m4!1s0x7007c9d931c86c5:0x1de0196a93401726!8m2 !3d-8.8137173!4d-36.95410 . Acesso em: 22 ago. 2016. 
GUTIERREZ, Rafaela Francisconi; ZANIN, Maria. A relação entre tecnologias sociais e economia solidária: um estudo de caso em uma cooperativa de catadores de

resíduos. Revista Brasileira de Desenvolvimento Regional, [s.I.], v. 1, n. 1, p.129-148, 1 abr. 2013.

INSTITUTO BRASILEIRO DE GEOGRAFIA E ESTATÍSTICA. IBGE Cidades. 2016.

Disponível em:

http://cidades.ibge.gov.br/xtras/perfil.php?codmun=260600\&search=pernambucolgaranhuns.

Acesso em: 13 ago. 2016.

JIANG, Yabing; SEIDMANN, Abraham. Capacity planning and performance contracting for service facilities. Decision Support Systems, [s.I.], v. 58, p.31-42, fev. 2014.

LEE, Chia-yen. Most productive scale size versus demand fulfillment: A solution to the capacity dilemma. European Journal of Operational Research, [s.I.], v. 248, n. 3, p.954962, fev. 2016.

LIMA, Rosimeire Suzuki; SILVA, Sandra Márcia Cesário Pereira. Evaluation of a municipal program of selective collection in the context of the national policy of solid waste. Acta

Scientiarum. Technology, [s.I.], v. 35, n. 4, p.645-653, 7 out. 2013.

MARCONDES, Celso Alexandre. A coleta Seletiva na cidade de Porto Alegre: uma visão sobre meio ambiente, economia e renda dos catadores. 2012. 89 f. Dissertação (Mestrado) Programa de Pós-graduação da Faculdade de Administração, Contabilidade e Economia, Pontifícia Universidade Católica do Rio Grande do Sul, Porto Alegre, 2012.

MARCONI, Marina de Andrade; LAKATOS, Eva Maria. Técnicas de

Pesquisa: planejamento e execução de pesquisas, amostragens e técnicas de pesquisa, elaboração, análise e interpretação de dados. 6. ed. São Paulo: Atlas, 2006.

MARQUES, Jerusa Gomes; SANTOS, Rosana Lopes dos. Analise do programa coleta seletiva com inclusão social e produtiva dos catadores. In: ENCONTRO INTERNACIONAL E NACIONAL DE POLÍTICA SOCIAL, 4. 2016, Vitória. Anais. Vitória: UFES, 2016.

MEDINA, Martin. Scavenger cooperatives in Asia and Latin America. Resources, Conservation And Recycling. [s. L.], p. 51-69. maio 2000.

MOREIRA, Daniel Augusto. Administração da produção e Operações. 2. ed. São Paulo: Cengage Learning, 2008.

MUNHOZ, José Renato; MORABITO, Reinaldo. Uma abordagem de otimização robusta no planejamento agregado de produção na indústria cítrica. Produção, [s.I.], v. 23, n. 2, p.422435, jun. 2013.

OLHAGER, Jan; JOHANSSON, Pontus. Linking long-term capacity management for manufacturing and service operations. Journal of Engineering and Technology Management, [s.I.], v. 29, n. 1, p.22-33, jan. 2012.

OLIVEIRA, Thais Brito de; GALVÃO JUNIOR, Alceu de Castro. Planejamento municipal na gestão dos resíduos sólidos urbanos e na organização da coleta seletiva. Engenharia Sanitária e Ambiental, [s.I.], v. 21, n. 1, p.55-64, mar. 2016.

PACHECO, Diego Augusto de Jesus et al. Modelo de gerenciamento da capacidade produtiva: Integrando Teoria das Restrições e o índice de rendimento operacional global (IROG). Produção Online, Florianópolis, v. 12, n. 3, p.806-826, jul. 2012. DOI:

https://doi.org/10.14488/1676-1901.v12i3.981

Revista Produção Online. Florianópolis, SC, v. 18, n. 4, p. 1344-1373, 2018. 
PAIVA, Ely Laureano; CARVALHO JUNIOR, José Mário de; FENSTERSEIFER, Jaime Evaldo. Estratégia de Produção e de Operações: Conceitos, melhores práticas, visão de futuro. Porto Alegre: Bookman, 2004.

PEINADO, Jurandir; GRAEML, Alexandre Reis. Administração da produção: operações industriais e de serviços. Curitiba: Unicenp, 2007.

PERGHER, Isaac; VACCARO, Guilherme Luís; PRADELLA, Maricelse. Aplicação da simulação computacional para determinar a capacidade produtiva do processo de produção de pães: um estudo de caso. Produto \& Produção, [s.l.], v. 14, n. 1, p.22-39, fev. 2013.

PERNAMBUCO. Secretaria de Meio Ambiente e Sustentabilidade - Semas. Governo do Estado de Pernambuco. Plano Estadual de Resíduos Sólidos. Recife: Governo do Estado de Pernambuco, 2012.

PERNAMBUCO. Lei $n^{\circ} 14.236$, de 13 de dezembro de 2010. Dispõe sobre a Política Estadual de Resíduos Sólidos, e dá outras providências. Recife, PE, 2010.

ROSA, Gilson et al. Reorganizing the layout as a production optimization strategy. Revista Gestão da Produção, Operações e Sistemas, [s.I.], v. 9, n. 2, p.139-154, 5 jul. 2014.

SILVA, Talita Floriano Goulart da; LEITE, Maria Silene Alexandre. A influência da gestão da capacidade na determinação do custo unitário de produção: um estudo de caso em uma empresa de embalagens plásticas flexíveis. Produção Online, Florianópolis, v. 13, n. 3, p.915-944, jul. 2013. DOI: https://doi.org/10.14488/1676-1901.v13i3.1233

SLACK, Nigel et al. Gerenciamento de operações e processos: Princípios e práticas de impacto estratégico. Porto Alegre: Bookman, 2008.

SLACK, Nigel; CHAMBERS, Stuart; JOHNSTON, Robert. Administração da produção. 3. ed. São Paulo: Atlas, 2009.

SOARES, Erika Leite de Souza Ferreira. Estudo da Caracterização Gravimétrica e Poder Calorífico dos Resíduos Sólidos Urbanos. 2011. 133 f. Dissertação (Mestrado) - Curso de Engenharia Civil, Universidade Federal do Rio de Janeiro, Rio de Janeiro, 2011.

SOARES, João Pedro Castelo-branco. Planeamento e aumento da capacidade de produção de rolhas técnicas e aglomeradas. 2010. 54 f. Dissertação (Mestrado) - Curso de Mestrado Integrado em Engenharia Industrial e Gestão, Faculdade de Engenharia da Universidade do Porto, Porto, 2010. Disponível em: https://repositorioaberto.up.pt/handle/10216/58221 . Acesso em: 14 set. 2016.

SOUZA, Fernanda Siqueira; PEDRINI, Danilo Cuzzuol; CATEN, Carla Schwengber Ten. Proposta de fluxograma orientativo para aplicação de índices de capacidade. Gest. Prod., [s.l.], v. 21, n. 4, p.882-894, dez. 2014.

SOUZA, Tiago Augusto Amarante de et al. Computational simulation and lean thinking as tools of process management: an assessment of different alternatives to increase capacity in a manufacturing company of aluminum electrical cables. Revista Gestão da Produção, Operações e Sistemas, [s.I.], v. 9, n. 4, p.125-138, 4 dez. 2014.

STAUDT, Francielly Hedler; COELHO, Antonio Sérgio; GONÇALVES, Mirian Buss. Determinação da capacidade real necessária de um processo produtivo utilizando cadeia de Markov. Produção, [s.I.], v. 21, n. 4, p.634-644, 2011.

Revista Produção Online. Florianópolis, SC, v. 18, n. 4, p. 1344-1373, 2018. 
WILSON, David C.; VELIS, Costas; CHEESEMAN, Chris. Role of informal sector recycling in waste management in developing countries. Habitat International, [s.I.], v. 30, n. 4, p.797808, dez. 2006.

XIE, Wenming et al. Capacity planning and allocation with multi-channel

distribution. International Journal Of Production Economics, [s.I.], v. 147, p.108-116, jan. 2014.

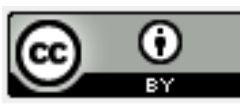

Artigo recebido em: 21/02/2017 e aceito para publicação em: 02/10/2018

DOI: http://dx.doi.org/10.14488/1676-1901.v18i4.2945 